\title{
Effect of Machining Cusps on the Stress Concentration Factor on Curved Surface
}

\author{
Md Shams E Tabriz and Simon Barrans \\ University of Huddersfield, Huddersfield, United Kingdom \\ Email: Md.S.Tabriz@hud.ac.uk,S.Barrans@hud.ac.uk
}

\begin{abstract}
Recently multi-axis machining technology has improved significantly. It has become a widely accepted method of manufacturing components with complex, free form surfaces. Solid billet materials with negligible internal defects are used in this process. This provides increased durability and fatigue life over equivalent cast components. However, multi-axis machining using ball nose cutting tools leaves cusps as machining marks. The combination of tool size and step-over generates cusps with different depths and widths. Even though the cusps add extra material on top of the nominal surface, Finite Element Analysis (FEA) shows the maximum stress generated within the cusps is greater than that predicted from the cusp-free geometry. These stress concentrations generated by cusps can reduce the fatigue life and durability of a machined component.

This paper reports FEA results; simulating the effect of cusps on surfaces with a range of curvatures for a fixed tool size and six different cusps depth. The FEA results show that the stress concentrations due to surface curvature and cusps can be determined independently and then multiplied together to give the combined stress concentration factor. The results of this analysis will allow designers to specify a maximum machining cusp depth on a curved surface.
\end{abstract}

Index Terms-Multi-axis machining, cusps, machining marks, finite element analysis, stress concentration, surface curvature

\section{INTRODUCTION}

Multi-axis machining is a standard manufacturing process widely used by the automotive and aerospace industries. Ball nose tools are used on workpieces with complex surfaces and for finishing operations. Multi-axis machining processes using ball nose cutting tools may leave significant machining marks in the form of cusps. According to Vickers and Quan [1], cusps form between adjacent cutter paths across the surface. Squires [2] pointed out that the depth of the cusp depends on the combination of tool diameter size and the distance between each pass or step over of the machine tool head. Cusps are extra material laying on top of the nominal geometry and this machined surface is typically a non-functional surface. Figure 1 shows an example of a

Manuscript received November 30, 2017, revised August 9, 2018.

This work was supported in part by the regional growth fund provided by UK Government (RGF Grant Award 01.09.07.01/1789C). machined non-functional surface with machining cusps. In this example, the only purpose of the surface is to guide the flow of air through the compressor. To reduce production times, deep cuts and large step overs are used leaving significant cusps on the curved surface. The surface curvature varies significantly from the blade root to hub area.

Researchers have investigated the effect of the surface roughness of specimens machined by turning on stress, fatigue life and durability. Bayoum \& Abdellatif [3], Javidi et al. [4] and Sasahara [5] have looked into the effect of surface roughness on the fatigue life of aluminium alloy, nickel-molybdenum alloy and $0.45 \% \mathrm{C}$ steel respectively and concluded that the fatigue durability reduces with increasing surface roughness due to the stress concentrations generated by the rough surface. Novovic et al. [6] state that surface roughness values over $0.1 \mu \mathrm{m}$ influence the fatigue life on any component significantly. Schmid et al. [7] suggest using a surface finish factor, $k_{f}$, to include the effect of surface roughness on fatigue life. This surface finish factor is used to calculate the modified fatigue endurance limit, $S_{e}$, as:

$$
S_{e=} k_{n} \times k_{f} \times S_{e}^{\prime}
$$

Here, $S_{e}^{\prime}=$ Endurance limit in ideal condition $k_{n}=$ Size, temperature and other factors

The surface finish factor can be calculated by [8] :

$$
K_{f}=e S_{u t}^{f}
$$

Here,

$S_{u t}=$ Ultimate Tensile Strength of Material, $\mathrm{MPa}$

$e \& f=$ Empirical factors depending on the manufacturing process. For machining

$$
e=4.51 \mathrm{nd} f=-.265
$$

Suraratchai et al. [9] and As et al. [10], both used Finite Element Analysis (FEA) of measured topologies of machined surfaces without cusps to calculate the stress concentration induced by surface roughness. The surfaces were measured using a diamond stylus instrument and an optical surface profiler respectively. The authors used the stress concentration data to calculate the fatigue life of the component. To validate the simulations, Suraratchai et al. 
[9] used a solid aluminium bar and four-point bending fatigue tests. In contrast, As et al. [10] used a cylindrical specimen and tensile fatigue tests. Tabriz \& Barrans [11] used FEA to determine the stress concentration generated by cusps on a nominally flat specimen. A full factorial analysis of the effect of tool size, step over and cusp direction angle was conducted. It was found that tool size and step over were interacting factors which could be replaced by cusp depth. Cusps lying perpendicular to the first principal stress direction generated the largest stress concentration factors.

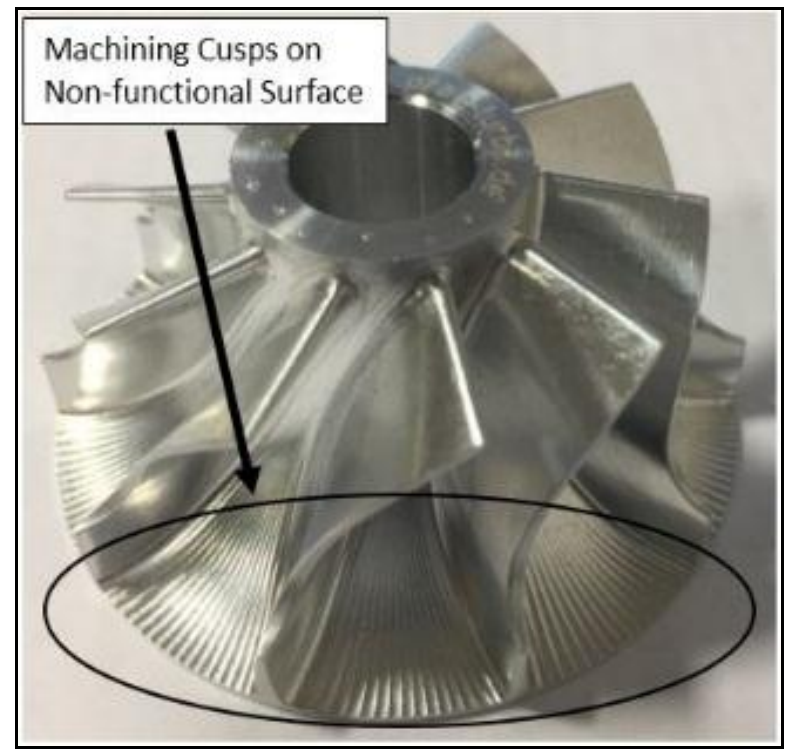

Figure 1. Non-functional Machined Surface on a Turbo-compressor Wheel.

Both Pilkey \& Pilkey[12] and Collins, Busby \& Staab[13] demonstrated that stress concentration factors caused by different geometric features can be multiplied to achieve the combined stress concentration factor.

In the work discussed above, the majority of researchers have only looked into the effect of surface roughness of machined surfaces without cusps on fatigue stress. Machining cusps have a significant effect on the surface geometry of any component [1], which may affect the performance. For example, Childs \& Noronha [14] investigated the effect of machining cusp on the aerodynamic performance of compressor impeller. Tabriz \& Barrans [11] only investigated the effect of cusps on stress concentration for flat surfaces. In this paper, FEA is used to investigate changes in the stress magnitude and distribution due to machining cusps formed by a $2 \mathrm{~mm}$ ball nose tool size on curved surfaces.

\section{DeVElopment OF ThE SPECIMEN}

\section{A. Flat Specimen}

Fig. 2 shows the traditional 'dog-bone' flat fatigue specimen developed for FEA simulation. The maximum stress is predicted to occur in the centre of the specimen where the width is smallest.

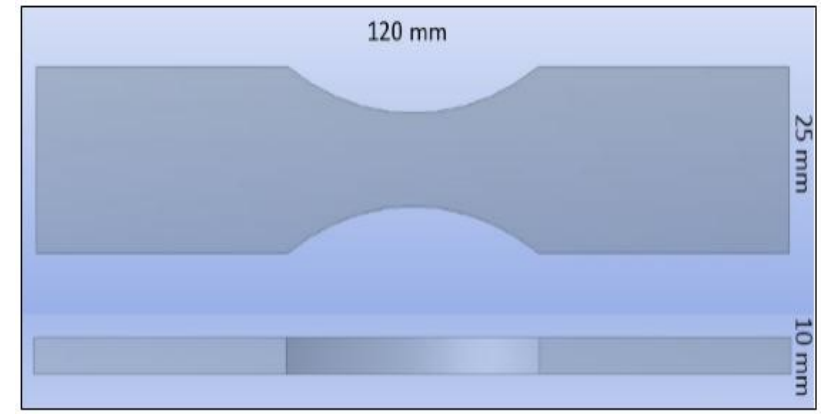

Figure 2. Tensile Specimen with Dimensions

\section{B. Curved Specimen}

To investigate the combined effect of both surface curvature and cusps, a second curvature was introduced to the traditional 'dog-bone' specimen, as shown in Figure 3. The arrow indicates the curvature direction. The maximum stress is predicted to occur in the centre of the specimen where the width and depth of the model are smallest.

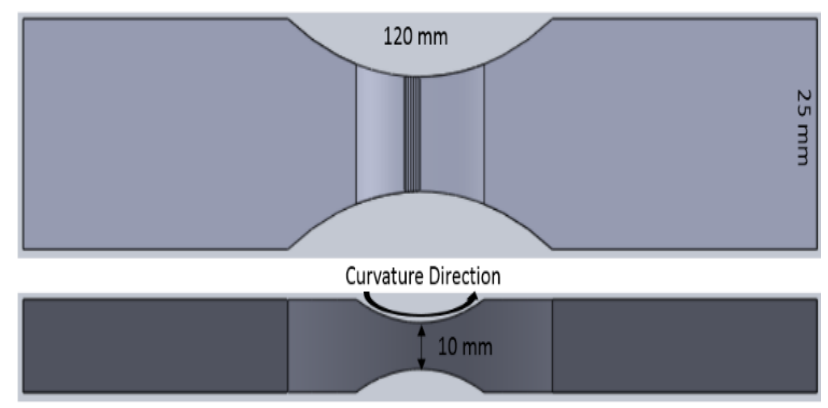

Figure 3. Curved Specimen with Dimensions

\section{NOMINAL StRESS \& StRESS CONCENTRATION FACTOR}

\section{A. Nominal Stress}

The nominal stress was defined as:

$$
\text { Nominal Stress }=\frac{\text { Force }}{\text { Cross Sectional Area }}
$$

Figure 4 shows the cross-sectional area of both specimens. The depth of the specimens is measured to the bottom of the cusp which is bisected by the plane of symmetry.

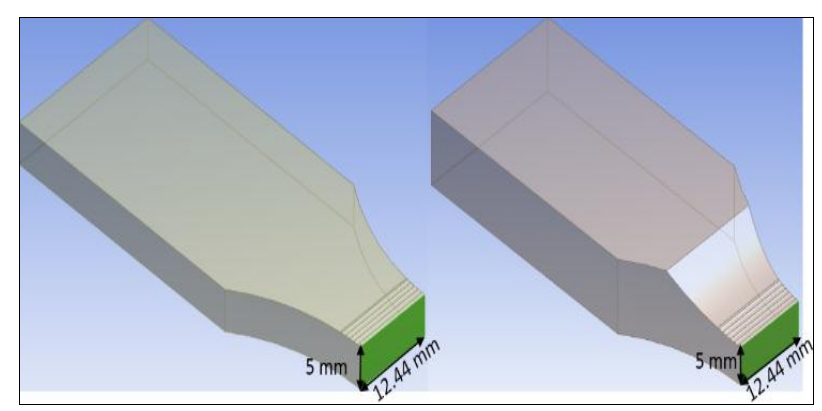

Figure 4. Cross Sectional Area of Flat and Curved Specimen. 
The cross-sectional area of a quarter of both specimens was $62.2 \mathrm{~mm}^{2}$ so for a $1 \mathrm{kN}$ tensile force, the nominal stress was $16.1 \mathrm{MPa}$. The cross-sectional area of a quarter of the specimen was considered as only $1 / 8^{\text {th }}$ of the specimen was used for the FEA simulations.

\section{B. Stress Concentration Factor}

The stress concentration factors (SCF) reported in this paper were calculated by using the equation:

$$
S C F=\frac{\text { Stress from FEA }}{\text { Nominal Stress }}
$$

\section{FEA SIMULATION OF FLAT SPECIMEN WITH CUSPS}

\section{A. Generation of Cusps}

Cusps were generated in the flat specimen in Ansys Design Modeller following the method used by Tabriz and Barrans [11]. A similar approach was taken to generate cusps in the curved specimen. The curvature radius was used to convert linear step-over to angular displacement. These angular displacement values were then used to construct the cusps as shown in Figure 5.

\section{B. Load and Constraints}

The stress distribution in the tensile specimen was determined using FEA. The specimen geometry and response were symmetric about 3 planes so $1 / 8^{\text {th }}$ of the model was used

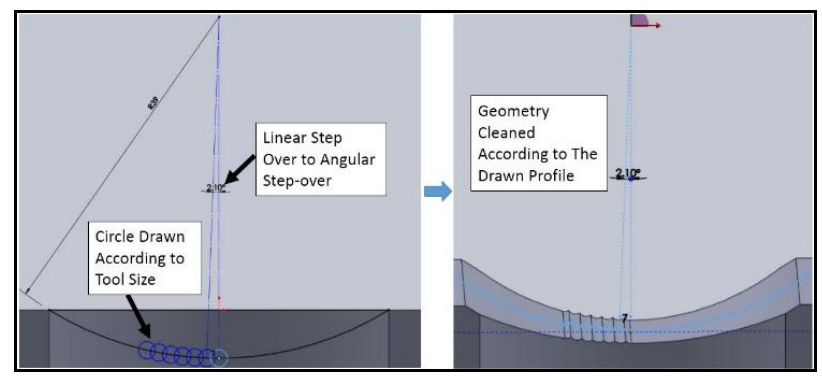

Figure 5. Generation of Cusps on Curved Surface

for the FEA simulation. The benefits of using a symmetric model of the tensile specimen models over the whole specimen are:

- The constraints required to prevent rigid body motion of the $1 / 8^{\text {th }}$ model are unambiguous: there can be no displacement of nodes on a plane of symmetry perpendicular to that plane.

- Using symmetry substantially reduces the FEA solution time for a given size of mesh.

- Mesh density can be increased to ensure convergence.

The load and constraints used for the simulation are shown in Fig. 6.

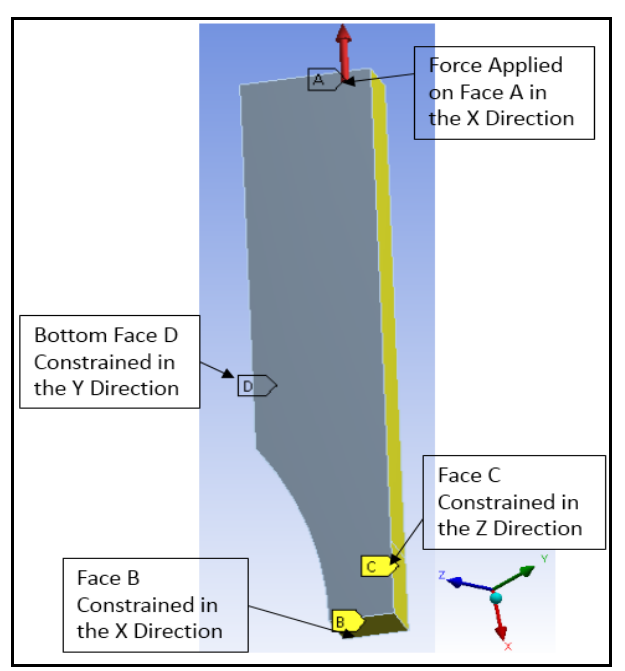

Figure 6 . The load and constraints used for the quarter model.

\section{Meshing Specimen with Cusps}

A fine mesh is necessary to represent the detailed cusp geometry on the specimen. Hence, a mesh convergence study was conducted on the element size in the machining cusp area. The element size for the rest of the specimen was kept as $0.4 \mathrm{~mm}$. Fig. 7 shows the results of the convergence study for the machining cusp area with a cusp height of $0.9 \mathrm{~mm}$. This is the largest cusp height used for this analysis. Based on the convergence study, localised mesh sizing of $0.15 \mathrm{~mm}$ was specified for $0.9 \mathrm{~mm}$ cusps as shown in Fig. 8. This element size allowed more than ten elements between the peaks of the cusps. This relative mesh size was maintained for smaller cusps.

The benefits of using localised meshing were:

- Smaller elements in the machining cusps better represented these cusps and allowed the effect of these to be captured.

- Simulation time was significantly reduced by using bigger elements in areas of low stress gradient.

\section{Simulation Results}

The cusps were generated using a fixed tool diameter of $2 \mathrm{~mm}$ generating cusp depths of $0.025 \mathrm{~mm}, 0.05 \mathrm{~mm}$, $0.1 \mathrm{~mm}, 0.3 \mathrm{~mm}, 0.5 \mathrm{~mm}$ and $0.9 \mathrm{~mm}$. This range of cusp height was chosen as for a tool diameter of $2 \mathrm{~mm}$; the cusps cannot be deeper than $1 \mathrm{~mm}$. The simulation results in figure 9 show the maximum stress in the predicted area of the specimen.

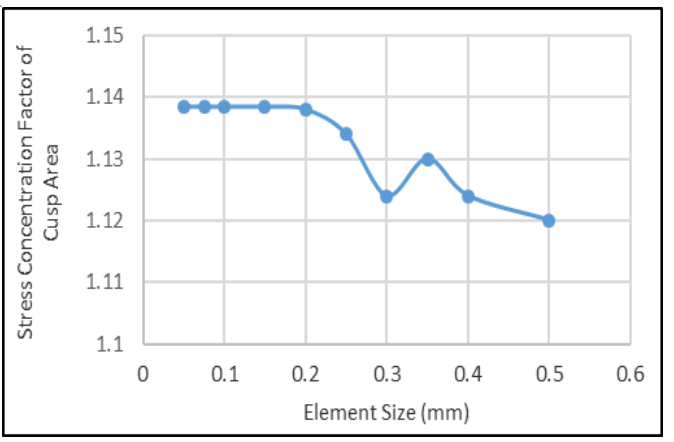

Figure 7. Mesh Convergence Study of Specimen with Machining Cusps. 


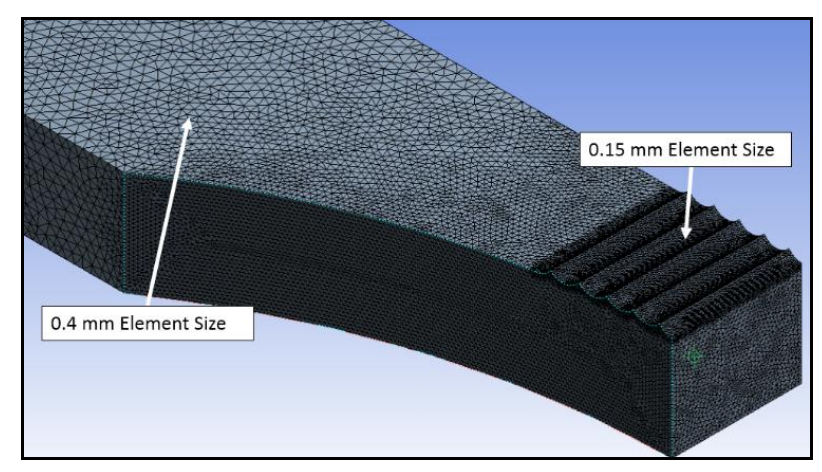

Figure 8. Localised Mesh Sizing.

The simulation results of all the cusp heights summarised in figure 10 show that as cusp height increases, the stress concentration factor increases. The dog bone radius was fixed for these flat specimens with different cusp heights. Therefore, cusp height was the only stress factor affecting the increase in stress concentration factor.

The results showed that stress concentration could increase up to $39 \%$ due to increasing cusp depth for a tool diameter of $2 \mathrm{~mm}$.

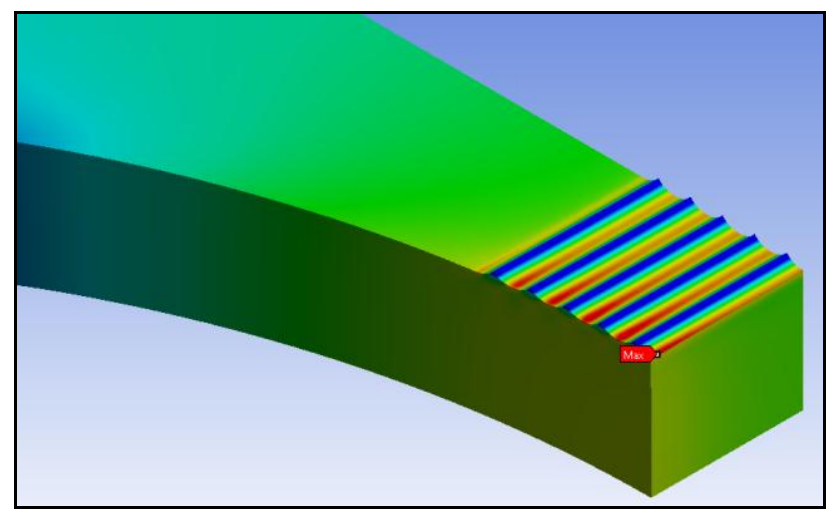

Figure 9. FEA results of specimen with cusps.

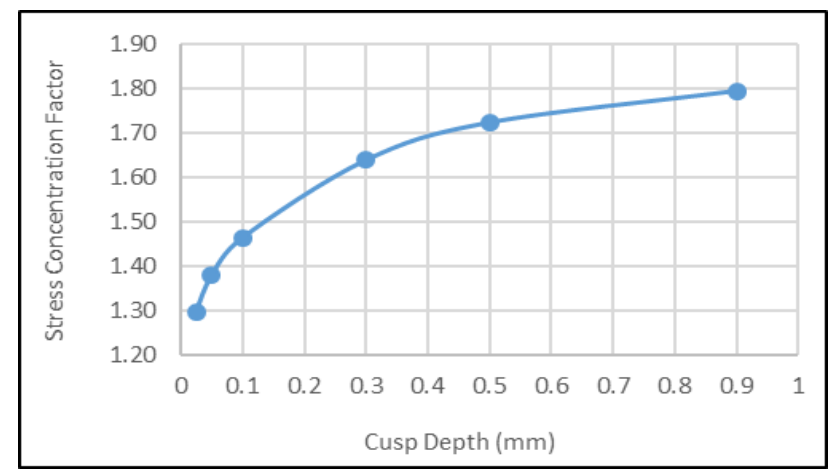

Figure 10. Effect of Cusp Height on the SCF of Flat Dog Bone Specimen.

\section{Simulation OF CURVEd SPECIMENS WITH CUSPS}

\section{A. Simulation Method}

As for the flat specimen, cusps were generated using a $2 \mathrm{~mm}$ tool diameter and the same cusps depths of $0.025 \mathrm{~mm}$, $0.05 \mathrm{~mm}, 0.1 \mathrm{~mm}, 0.3 \mathrm{~mm}, 0.5 \mathrm{~mm}$ and $0.9 \mathrm{~mm}$. Surface curvature radii of $5 \mathrm{~mm}, 10 \mathrm{~mm}, 15 \mathrm{~mm}, 20 \mathrm{~mm}, 40 \mathrm{~mm}$, $80 \mathrm{~mm}, 160 \mathrm{~mm}$ and $320 \mathrm{~mm}$ were considered.
The load and constraints used for the simulation of the curved specimen were identical to those used for flat specimen shown in Fig. 6.

\section{B. Simulation Results}

The stress concentration factors calculated from the results of all the simulations are shown in Figure 11. It can be seen that with an increasing radius of curvature, stress concentration factor decreases. As with the flat specimen, stress concentration increases with cusp depth. These stress concentration factor changes are only due to cusp depth and curvature as the dog bone radius was fixed. The results demonstrate that a smaller curvature radius magnifies the stress raising effect of the cusps. For example, at a curvature radius of $5 \mathrm{~mm}$ and cusp depth of $0.9 \mathrm{~mm}$, the stress concentration factor is $43 \%$ higher than for the same cusp depth with a curvature radius of $320 \mathrm{~mm}$. It can also be seen that those results converge towards those of the flat specimen as the curvature radius becomes large.

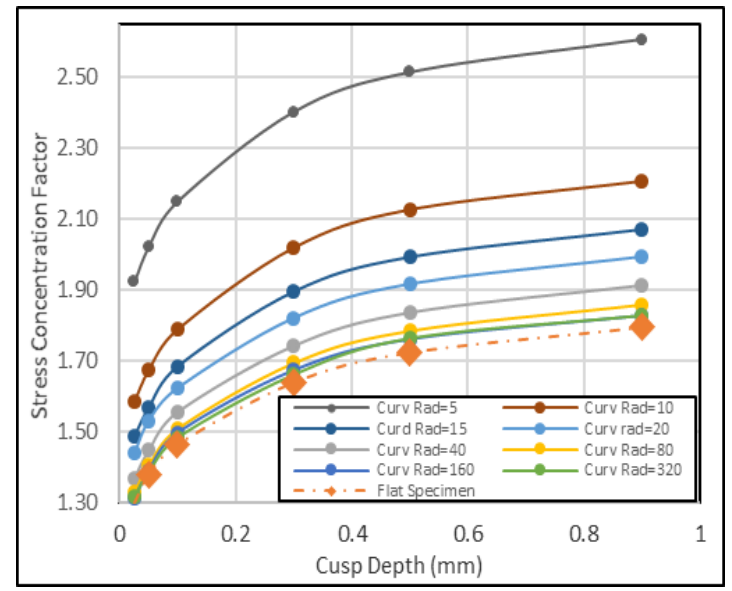

Figure 11. Effect of Cusp Height on Stress Concentration Factor of Curved Specimen and Comparison of Stress Factor with Flat Specimen.

\section{COMBINED STRESS CONCENTRATION FACTOR}

Specimens were generated with the dog bone, cusps and curvature geometric features isolated. This allowed the individual stress concentration factors generated by these features to be investigated. Figure 12 shows the $1 / 8^{\text {th }}$ symmetric models used for this investigation. Load and constraints used for these analyses were similar to the previous FEA analysis. The cusp model was replicated for six different cusp heights and the curvature model for eight different radii.

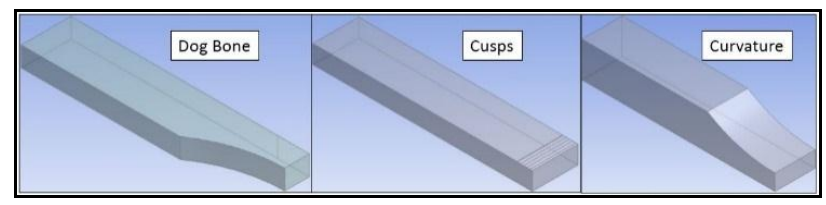

Figure $12.1 / 8^{\text {th }}$ of the Specimen with Individual Geometric Feature.

The dog bone radius used for all the specimens was $35 \mathrm{~mm}$, and the stress concentration factor generated by the dog bone feature was 1.1204 (using equations $3 \& 4$ ). Stress concentration factors generated by dog bone radii of 
50 and $65 \mathrm{~mm}$ were also calculated. The results shown in Figure 13 indicate that variations in dog bone radius would have only a comparatively small effect on stress concentration.

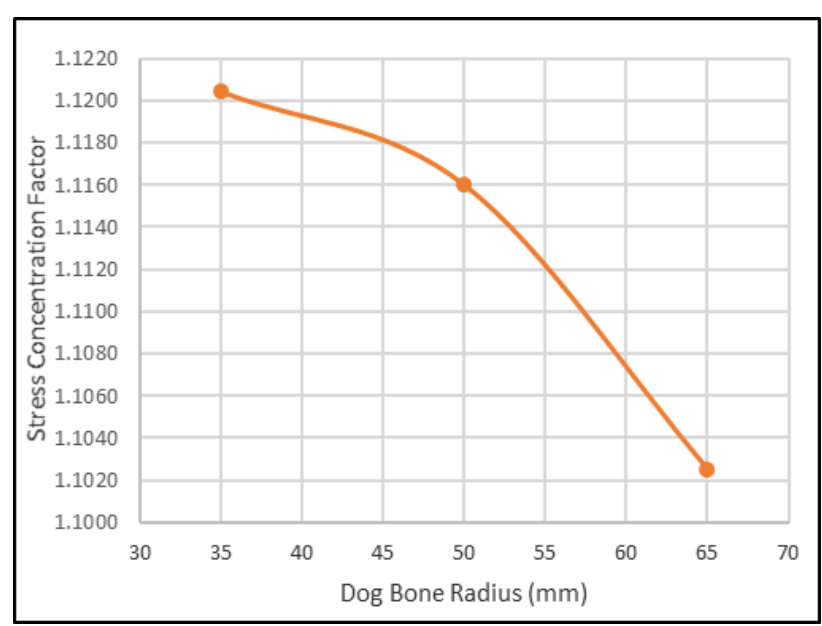

Figure 13. Stress Concentration Factor Generated by Only Dog Bone Radius.

\section{A. Stress Concentration Factor Generated by Cusps}

The range of cusps generated with a tool diameter of 2 $\mathrm{mm}$ as used in the previous analyses was generated individually to investigate the generated Stress Concentration Factor due to the cusp depth. Figure 14 shows the SCF generated by the range of cusps. The graph shows that the deeper cusps increase the SCF significantly.

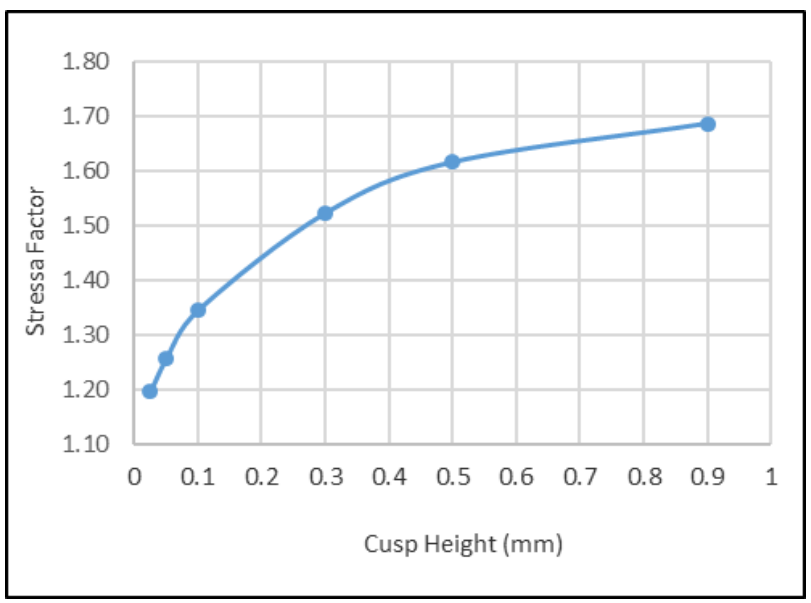

Figure 14. Stress Concentration Factor Generated by Only Cusps.

\section{B. Stress Concentration Factor Generated by Curvature}

The range of curvature radii used in the previous analyses were generated using the specimen shown in Fig. 12. The stress concentration factors generated by the curvature alone are shown in Figure 15.

The results show that a smaller curvature radius increases the SCF significantly whilst larger curvature radii have very little stress concentrating effect.

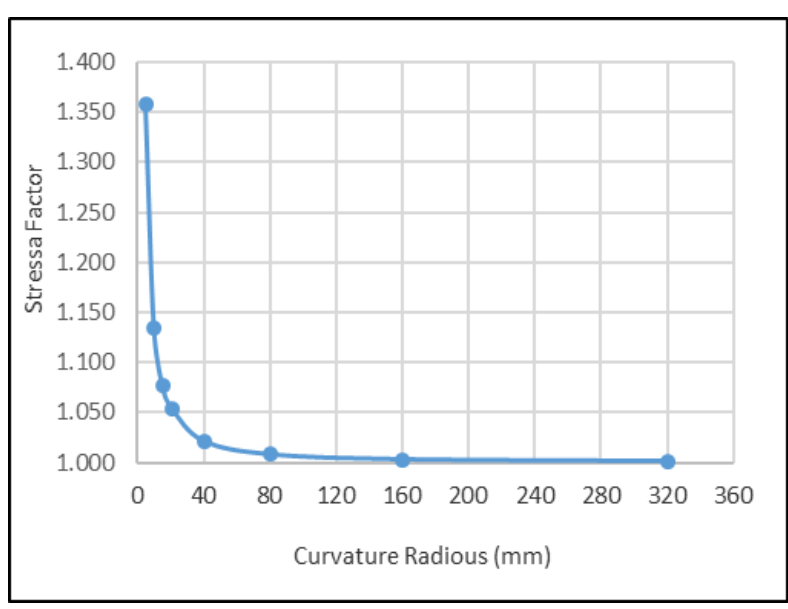

Figure 15. Stress concentration factor generated by cusps.

\section{Combination of Stress Concentration Factors}

Stress Concentration Factors (SCF) from individual dog bone, cusps and curvature radius were used to predict the total SCF, $K_{t \tau}$, using the equation.

Where,

$$
K_{t T}=K_{t d} K_{t r} K_{t c}
$$

$$
\begin{aligned}
& K_{t d}=\text { Dog-bone SCF } \\
& K_{t y}=\text { Curvature SCF } \\
& K_{\text {te }}=\text { Cusp SCF }
\end{aligned}
$$

These calculated combined SCF's were then compared with the with the SCF's from the FEA of the curved and flat specimens with cusps. Figure 16 shows the percentage difference between the calculated total SCF and the SCF from the FEA analysis. The method of combining multiple SCF predicts the SCF within an average absolute accuracy of $2.3 \%$.

The results show that the multiplication of individual SCF's over-predict the SCF for larger curvature \& flat specimen and under-predict the SCF for smaller curvatures. The interference among different geometric features can be a cause for this difference.

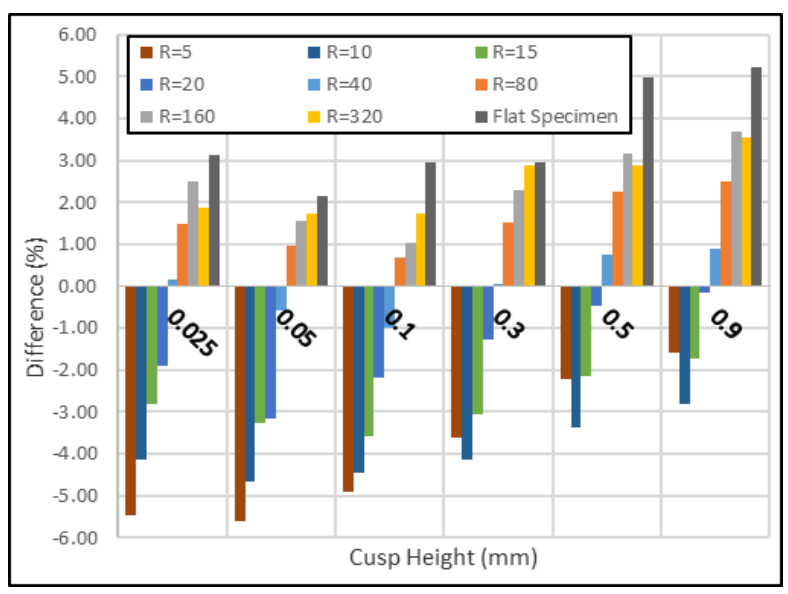

Figure 16: Comparison between Two of Methods of Calculating SCF. 


\section{CONCLUSION}

Ansys design modeller was used to replicate cusps with a variety of depths for a fixed tool size on both flat and curved specimens. Initial simulation on a flat specimen showed a significant increase in stress concentration factor with increasing cusp depth.

FEA simulation on the curved specimens showed that smaller curvature radii increased the stress concentration factor significantly. Large curvature radii had very little impact on the stress concentration factor. These results can be used to determine acceptable cusp depths for a range of surface curvatures.

The paper further shows that the cusp and curvature stress concentrations can be multiplied together to give an overall stress concentration factor accurate to within $7 \%$ of the combined analysis.

\section{REFERENCES}

[1] G. W. Vickers and K. W. Quan, "Ball-mills versus end-mills for curved surface machining," Journal of Engineering Industry, vol. 111, pp. 22-26, 1989.

[2] J. Squires, Understanding stepover and cusp height. 2013 [cited $2016 \quad 1 \quad$ November]; Available from: http://www.styrotechcnc.co.nz/our-blog/understanding-stepover-a nd-cusp-height.

[3] M. R. Bayoumi and A. K. Abdellatif, "Effect of surface finish on fatigue strength," Engineering Fracture Mechanics, vol. 51, no. 5, pp. 861-870, 1995.

[4] A. Javidi, U. Rieger, and W. Eichlseder, "The effect of machining on the surface integrity and fatigue life," International Journal of Fatigue, vol. 30, pp. 2050-2055, 2008.

[5] H. Sasahara, "The effect on fatigue life of residual stress and surface hardness resulting from different cutting conditions of $0.45 \%$ C steel," International Journal of Machine Tools \& Manufacture, vol. 45, pp. 131-136, 2005.

[6] D. Novovic, R. C. Dewes, D. K. Aspinwall, W. Voice, and P. Bowen, "The effect of machined topography and integrity on fatigue life," International Journal of Machine Tools \& Manufacture, vol. 44, pp. 125-134, 2004.

[7] S. R. Schmid, B. J. Hamrock, and B. O. Jacobson, Fundamentals of Machine Elements, 3rd ed. 2014, Boca Raton, FL, USA: CRC Press.

[8] J. E. Shigley and L. D. Mitchell, Mechanical Engineering Design. 4th ed. 1983, London: McGraw Hill.

[9] M. Suraratchai, J. Limido, C. Mabru, and R. Chieragatti, "Modelling the influence of machined surface roughness on the fatigue life of aluminium alloy," International Journal of Fatigue, vol. 30, pp. 2119-2126, 2008.

[10] S. K. As, B. Skallerud, and B. W. Tveiten, "Surface roughness characterization for fatigue life predictions using finite element analysis," International Journal of Fatigue, vol. 30, pp. 2200-2209, 2008.

[11] M. Tabriz and S. Barrans, "Effect of Cusp Size, Depth and Direction on Stress Concentration," International Journal of Materials, Mechanics and Manufacturing, vol. 5, no. 3, 2017.

[12] W. D. Pilkey and D. F. Plikey, Peterson's Stress Concentration Factors, Third ed. 2008, Hoboken, New Jersey: John Willey \& sons, Inc.

[13] J. A. Collins, H. Busby, and G. Staab, Mechanical Design of Machine Elements and Machines A Failure Prevention Perspective. 2010, United States: John Wiley \& Sons.

[14] P. R. N. Childs and M. B. Noronha, The Impact of Machining Techniques on Centrafugal Compressor Impeller Performance, in International Gas Turbine \& Aeroengine Congress \& Exhibition. 1997, ASME: Orlando, Florida, USA.

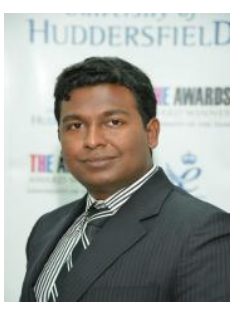

Md Shams E Tabriz was born in Bangladesh. He earned his bachelor's degree in Mechanical Engineering from the University of Huddersfield on 2014. He is currently a PhD student in the Turbocharger Research Institute (TRI) of the University of Huddersfield. His research area is micro-crack initiation and provpagation due to low cycle fatigue loading. The $\mathrm{PhD}$ project is funded by The UK government's Regional Growth Funding (RGF) and BorgWarner Turbo System.

Prior to start his $\mathrm{PhD}$, he has worked in General Motors UK as process and quality engineer.

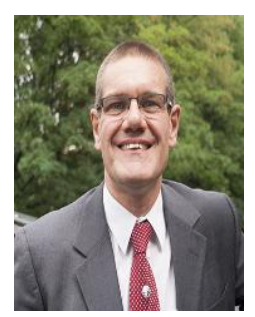

Simon Barrans gained a first degree in Nuclear Engineering at Manchester University and a PhD from the University of Huddersfield. Since joining the academic staff at the University of Huddersfield he has occupied various teaching and management positions including being Subject Area Leader in Mechanical and Automotive Engineering. $\mathrm{He}$ is currently the Reader in Turbocharger Engineering. He is an editor for the Open Engineering journal and a reviewer for seven international journals.

Simon Barrans' current research is on the structural integrity of turbocharger systems with a particular focus on the methods used to join turbocharger housings together, predicting the stress raising effect of tool marks on machined from solid components and stress analysis of rotors for very high speed electric machines. He has also investigated the use of foil bearings in turbochargers, an extension of his previous research work on air bearings.

Simon Barrans regularly collaborates with industry on research and development projects. He has managed six Knowledge Transfer Partnerships with industrial partners funded by Innovate UK, two of which were graded as 'outstanding' 